\title{
Power Analysis and Energy Storage Control in Distributed Generation System with Low Grid Voltage
}

\author{
Guohe Zhao* \\ China Potevio Company limited, Beijing, China 100080 \\ ${ }^{*}$ Corresponding author
}

\begin{abstract}
This paper presented an extensive analysis of dynamic change of power flow between distributed generators and loads in the situation of low grid voltage. And, a control strategy with energy storage to balance the power flow was proposed. First, the constant power control strategy of the distributed generators such as photovoltaic power generation and wind power generation was realized, and the output power flow of the voltage source converter was also analyzed. Second, with different types of system loads which were constant power load and constant impedance load, the dynamic process characteristics of the distributed generators and the loads were presented when the grid voltage was lower than the normal value. Finally, energy storage equipment was used to balance the power flow, and the control method of the energy storage was also presented. Based on these analyses, the characteristics of distributed generation system are obtained. Simulation investigation results are finally provided to verify the analysis and specification.
\end{abstract}

Keywords—distributed generation; low grid voltage; energy storage; power control

\section{INTRODUCTION}

Distributed Generations (DG) has attracted more and more attentions in the last several years. Normally, the DG may be photovoltaic power generator, wind power generator or energy storage equipment $[1,2]$. Renewable energy generations such as photovoltaic power generator, wind power generator are easily affected by the natural environment.

The voltage source inverter is used in the DG system. And, many control methods are proposed [3, 4]. In the grid-connected mode of DG, the PQ control is widely used to generate the active power and the reactive power [5]. The Maximum Power Point Tracking (MPPT) control can get a high generating efficiency in photovoltatic power generator and wind power generator [6].

The power flow between distributed generators and loads should be balanced in distributed generation system. If the low grid voltage occurs, the power flow will be changed. Some control strategies are proposed in the grid fault situation, in [7], the control strategy of low voltage ride through is presented to make the wind power generator operate normally when the low voltage occurs. And, the DG systems are required to remain connected to the grid for a certain period of time determined by the voltage limiting curve to allow disconnection. The limiting curves for voltage pattern in the grid connection mode of the DG are also presented in the event of the grid fault [8]. Furthermore, in [9], the analysis of the power qualities is carried out, and in
[10], some control methods of power quality improvement are got. The conclusions in these papers are very useful, and make contributes to the applications. However, the analysis of the power flow at the grid fault is seldom discussed, especially with different type of DG and loads. And the characteristics of the power flow in the situation of grid fault should be discussed in detail.

In this paper, an extensive analysis of dynamic power change is presented, and a control strategy with energy storage to balance the power flow is proposed. The output power flow of the voltage source converter is also analyzed. Second, with different types of system loads which are constant power load and constant impedance load, the dynamic process characteristics of the distributed generators and the loads are presented when the grid voltage is lower than the normal value. Finally, energy storage equipment is used to balance the power flow, and the control method of the energy storage is also presented.

\section{DG SYSTEM AND CONTROL STRATEGIES}

\section{A. DG System}

The DG system is shown in Figure I. There are several distributed generators such as photovoltaic power generation and wind power generation. A voltage source converter with a battery is in parallel with the load and the distributed generators. The load power is supplied by the grid and the distributed generators.

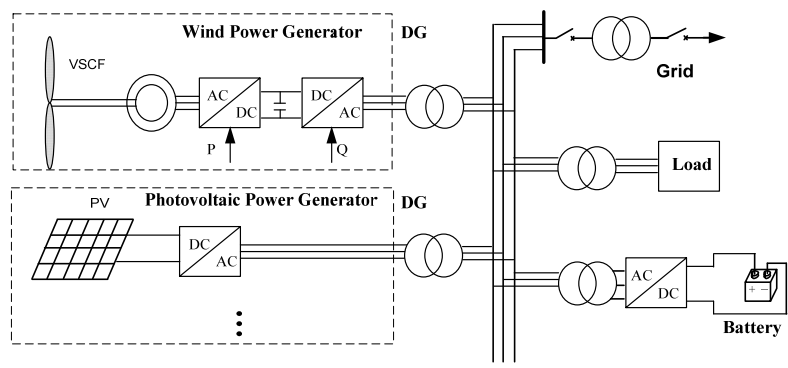

FIGURE I. DG SYSTEM

\section{B. Control Strategies}

In the DG system, the control strategy of wind power generation and the control strategy of photovoltaic power generation are investigated. 
In Figure II, the wind power generator can produce the active power to the grid, and the MPPT control method is usually to control the output active power. So, the PQ control is widely used in the wind power generation system. In this paper, a Permanent Magnet Synchronous Generator (PMSG) based wind power generation system is investigated. In the control strategy, a current control loop and a DC side voltage control loop/speed control loop are proposed.

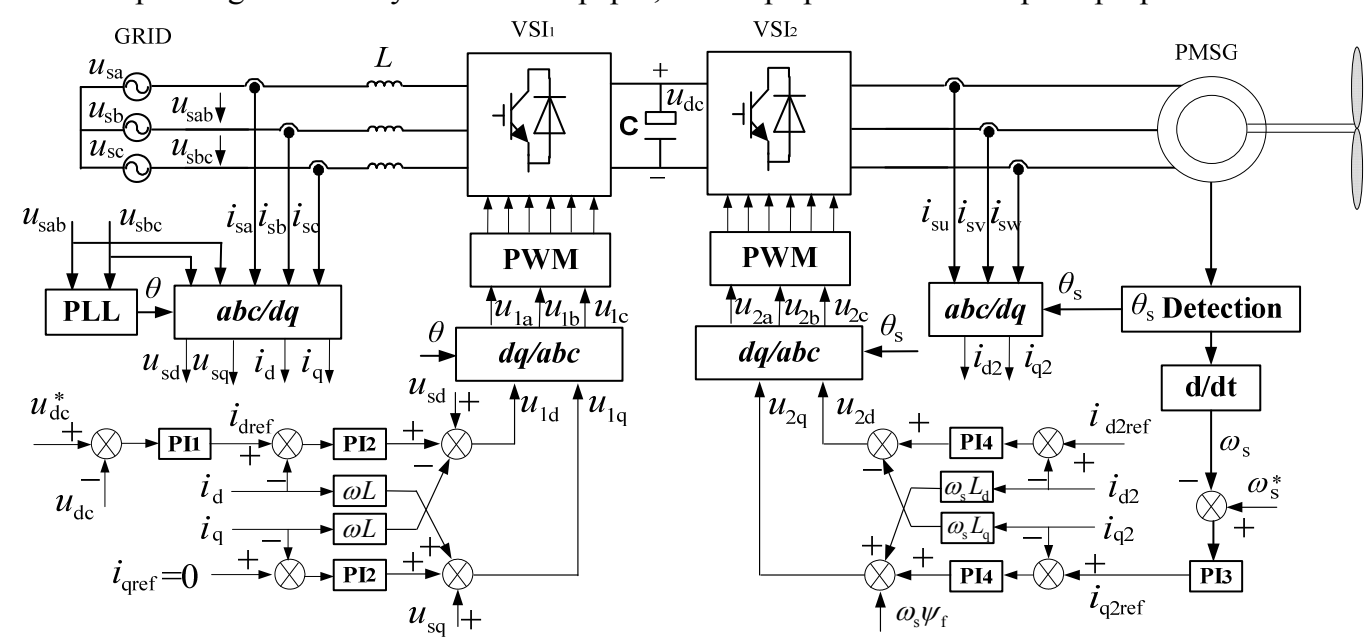

FIGURE II. CONTROL STRATEGY OF WIND POWER GENERATION

In Figure III, the photovoltaic power generator can produce the active power to the grid, and the MPPT control method is usually to control the output active power. In this paper, a DC/DC converter (Boost) and a grid-connected voltage source inverter are used to transfer the power and to boost the DC side voltage. In the voltage source inverter, the PQ control is also used. In the control strategy, a current control loop and a DC side voltage control loop are proposed.

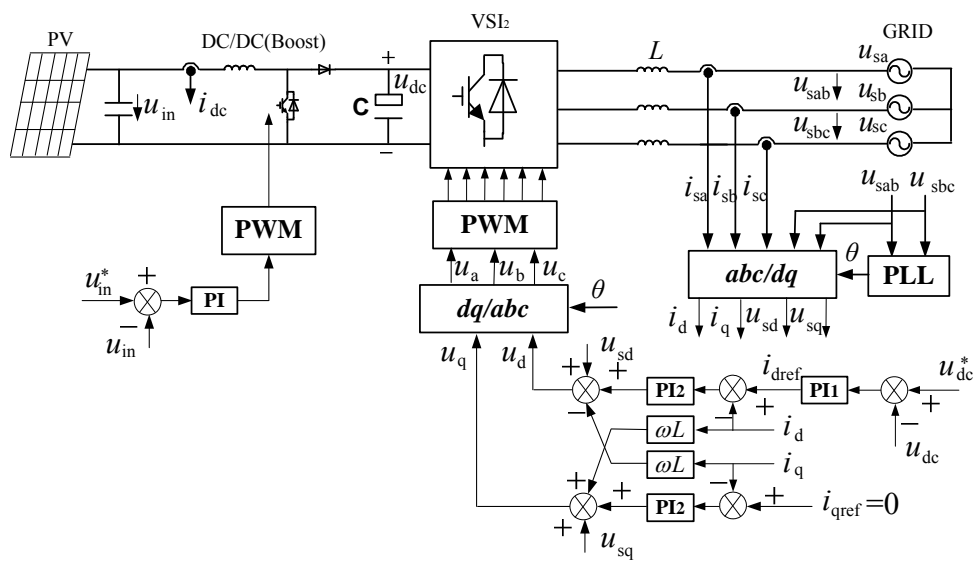

FIGURE III. CONTROL STRATEGY OF PHOTOVOLTAIC POWER GENERATION

\section{Characteristics of Distributed Generations With LOW GRID VOLTAGE}

In the grid-connected mode, the output power of distributed generations is determined by the power of the renewable energy generations. And, the PQ control of the voltage source inverter is used to transfer the power to the grid. If the grid voltage becomes to a low voltage value, the power generated by the distributed generations is not changed in a period of time, because the output power of renewable energy changes slowly. 


\section{A. Characteristic of Grid Power with Different Types of Loads}

When the low grid voltage happens, the characteristics of the grid power are different with different types of system loads. If the system load is a constant power load, the power flowing to the grid is not changed, because the output power of each distributed generator is not changed. In Fig. II and Fig. III, the current control loop of the voltage source inverter has a grid voltage forward component, and then, the low grid voltage does not affect the current control loop. As a result, the reference current generated by the DC side voltage control loop will be changed, because the power does not change and the grid voltage changes. Finally, the output current changes according to the reference current.

If the system load is a constant impedance load, the power flowing to the grid will be changed, because the output power of each distributed generator is not changed and the load power is changed. In this situation, the power fluctuation exists, and it might influence the power balance or the grid stability, especially, in large renewable energy capacity grid. The energy storage equipment is usually used to balance the change of the power during the period of the low grid voltage.

\section{B. Control of Energy Storage Equipment to Balance the Power Flow}

In Figure IV, the energy storage equipment can produce the active power to balance the power flow. In the control strategy, a current control loop and an active power control loop are proposed. If the value of the reference power is changed to the power error between the power of the distributed generators and the load power, the grid power will be controlled to a constant value in the low grid voltage situation.

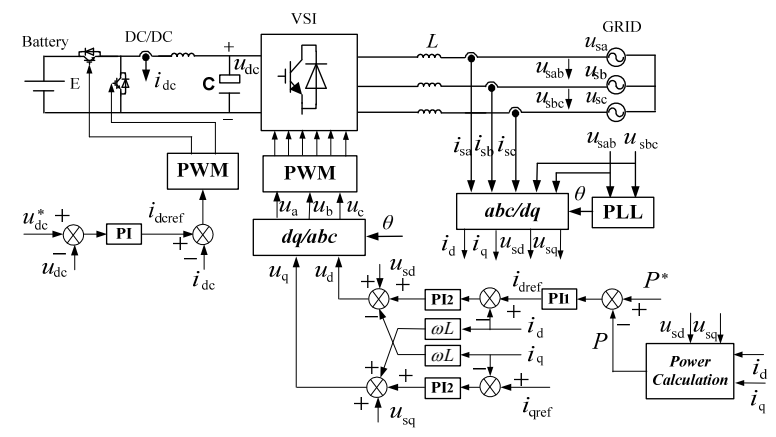

FIGURE IV. CONTROL STRATEGY OF ENERGY STORAGE EQUIPMENT

\section{SimUlATION}

In order to verify the analysis and specification, the simulation investigation were carried out.

\section{A. Output Characteristics of Distributed Generators with Low Grid Voltage}

In Figure V, when the low grid voltage happened, the output current of the wind power generation will be changed and the output power will not be changed because the output power was determined by the wind power generator. In Figure VI, when the low grid voltage happened, the output current of photovoltaic power generation will be changed and the output power will not be changed because the output power was determined by the photovoltaic power generator.

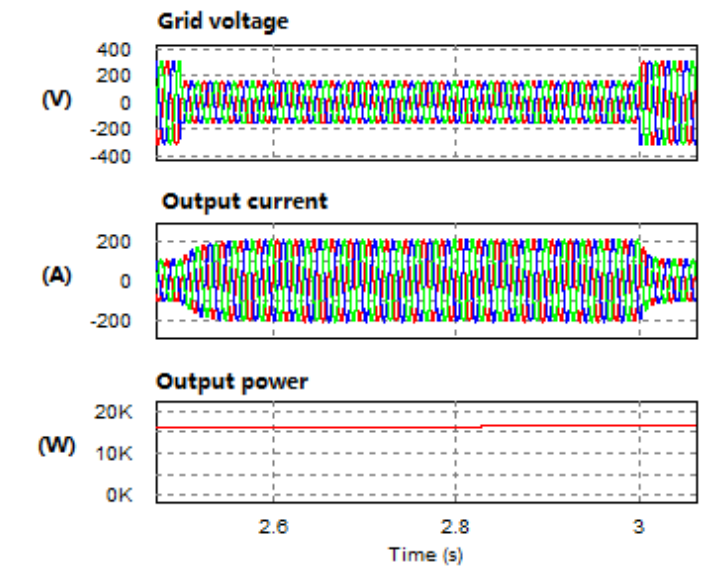

FIGURE V. OUTPUT CURRENT AND OUTPUT POWER OF WIND POWER GENERATION WITH LOW GRID VOLTAGE

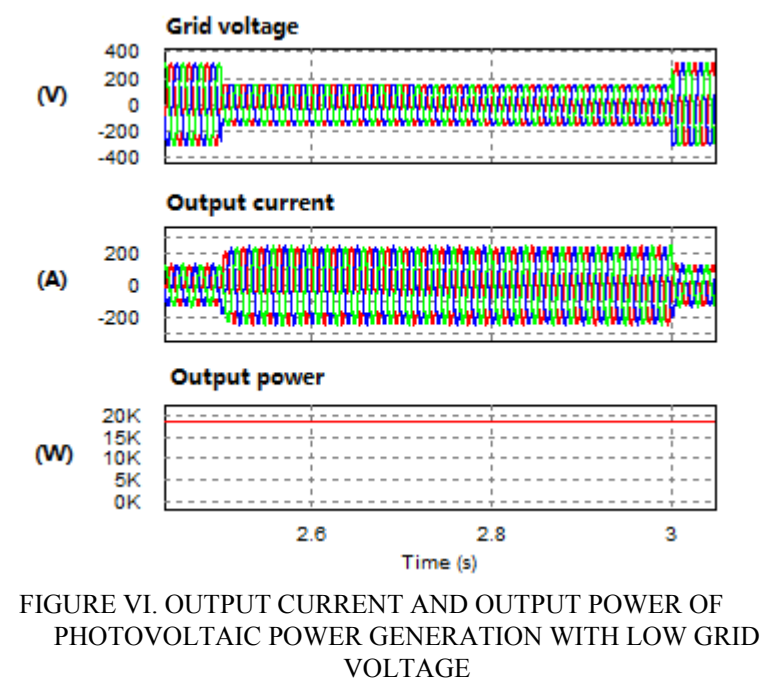

\section{B. Characteristics of Grid Power with Low Grid Voltage}

For the constant power system load, in Figure VII, when the low grid voltage happened, the grid power will not be changed because the power of the distributed generations and the load was not changed. For the constant impedance system load, in Figure VIII, when the low grid voltage happened, the grid power was changed because there was a power error between the distributed generators and the load. In Figure IX, if the energy storage equipment was used to compensate the power error, the grid power can be control to a constant power value. 
(v)
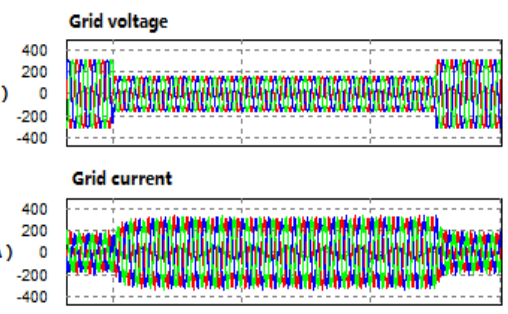

Grid power

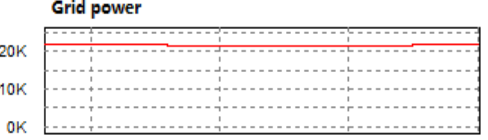

Load current

(A) 0

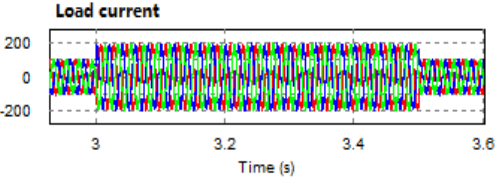

FIGURE VII. GRID POWER WITH CONSTANT POWER SYSTEM LOAD
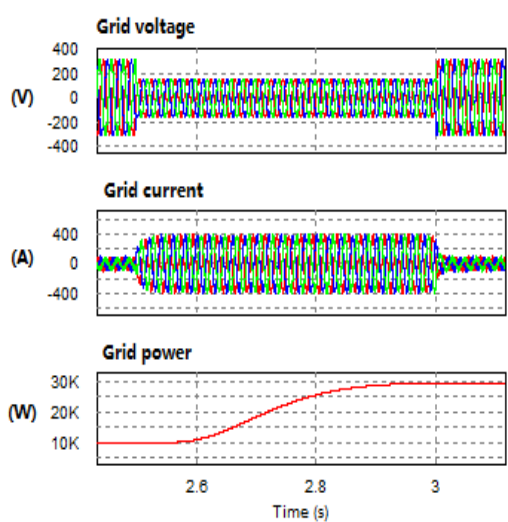

FIGURE VIII. GRID POWER WITH CONSTANT IMPEDANCE SYSTEM LOAD

( $\mathrm{V})$
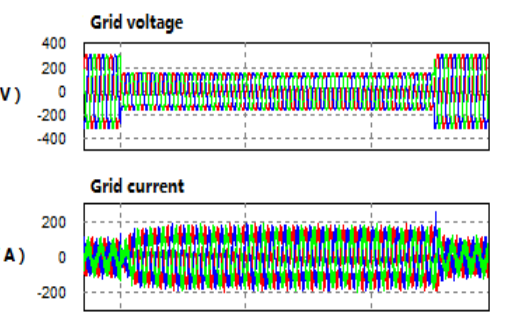

$$
\text { Grid power }
$$

(W)
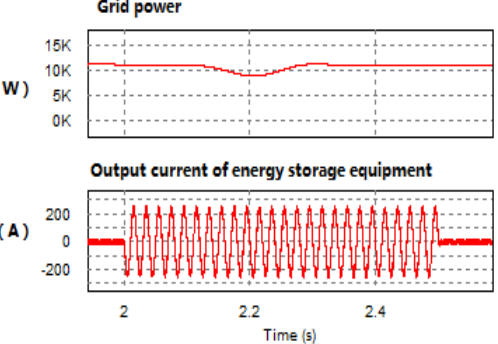

FIGURE IX. GRID POWER BALANCED BY THE ENERGY STORAGE EQUIPMENT

The simulation results verified the analysis and the conclusion.

\section{Conclusions}

In this paper, an extensive analysis of dynamic power change is presented under the low grid voltage condition, and a control strategy with energy storage to balance the power flow is proposed. In the distributed generations, because the grid voltage forward component exists in the current control loop, the influence of the low grid voltage on the current control loop is very small, and the output power of the distributed generations will not be changed, as a result, the output current reference and the output current are changed. With the constant power system load, the grid power will not be changed. And, with the constant impedance system load, the grid power will be changed. The energy storage equipment can be used to balance the power flow, and the power value is equal to the power error between the distributed generators and the loads.

\section{REFERENCES}

[1] Ikki Tanaka, Hirokana Yuge, Hiromitsu Ohmori. Formulation and evaluation of long-term allocation problem for renewable distributed generations, IET Renewable Power Generation, 2017, 11(12): 1584-1596.

[2] Stefanos Baros, Marija D. Ilić. Distributed Torque Control of Deloaded Wind DFIGs for Wind Farm Power Output Regulation, IEEE Transactions on Power Systems, 2017, 32(6): 4590-4599.

[3] Wei Liu, Wei Gu, Yinliang Xu, Yong Wang, Kaifeng Zhang. General distributed secondary control for multi-microgrids with both PQ-controlled and droop-controlled distributed generators, IET Generation, Transmission \& Distribution, 2017, 11(3): 707-718.

[4] Xiaoqing Lu, Xinghuo Yu, Jingang Lai, Josep M. Guerrero, Hong Zhou. Distributed secondary voltage and frequency control for islanded microgrids with uncertain communication links, IEEE Transactions on Industrial Informatics, 2017, 13(2): 448-460.

[5] Samuele Grillo, Stefano Massucco, Andrea Morini, Andrea Pitto, Federico Silvestro. Microturbine control modeling to investigate the effects of distributed generation in electric energy networks, IEEE Systems Journal, 2010, 4(3): 303-312.

[6] Bailu Xiao, Lijun Hang, Jun Mei, Cameron Riley, Leon M. Tolbert, Burak Ozpineci. Modular cascaded H-bridge multilevel PV inverter with distributed MPPT for grid-connected applications, IEEE Transactions on Industry Applications, 2015, 51(2): 1722-1731.

[7] Yidong Chen, Yulin Yang, Liqiao Wang, Weiyang Wu. A low voltage ride-through control strategy of full power converter wind turbine system under balance grid fault, 2011 International Conference on Electrical Machines and Systems, 2011, 1-6.

[8] Thanh Hai Nguyen, Dong-Choon Lee. LVRT and power smoothening of DFIG-based wind turbine systems using energy storage devices, ICCAS 2010, 2010, 1070-1074.

[9] Josep M. Guerrero, Poh Chiang Loh, Tzung-Lin Lee, Mukul Chandorkar. Advanced control architectures for intelligent microgrids-part II: power quality, energy storage, and AC/DC microgrids, IEEE Transactions on Industrial Electronics, 2013, 60(4): 1263-1270.

[10] K. P. Preetha , B. Jayanand, P. Reji. Power quality enhancement using Distributed Generation inverters with active power control, 2015 International Conference on Technological Advancements in Power and Energy (TAP Energy), 2015, 205-210. 